\title{
BMJ Open Observational cohort study to investigate the unmet need and time waiting for referral for specialist opinion in adult asthma in England (UNTWIST asthma)
}

\author{
John D Blakey, ${ }^{1,2}$ Alicia Gayle, ${ }^{3}$ Mariel G Slater (1) , ${ }^{4}$ Gareth H Jones, ${ }^{5}$ \\ Michael Baldwin ${ }^{6}$
}

To cite: Blakey JD, Gayle A, Slater MG, et al. Observational cohort study to investigate the unmet need and time waiting for referral for specialist opinion in adult asthma in England (UNTWIST asthma). BMJ Open 2019;9:e031740. doi:10.1136/ bmjopen-2019-031740

- Prepublication history and additional material for this paper are available online. To view these files, please visit the journal online (http://dx.doi. org/10.1136/bmjopen-2019031740).

Received 16 May 2019

Revised 01 November 2019

Accepted 04 November 2019

D) Check for updates

(C) Author(s) (or their employer(s)) 2019. Re-use permitted under CC BY-NC. No commercial re-use. See rights and permissions. Published by BMJ.

For numbered affiliations see end of article.

Correspondence to Dr Mariel G Slater; mariel.slater@boehringeringelheim.com

\section{ABSTRACT}

Objectives This study aimed to estimate how many patients with asthma in England met the referral eligibility criteria using national asthma guidelines, identify what proportion were referred and determine the average waiting time to referral.

Design This is an observational cohort study.

Setting/Data sources Routinely collected healthcare data were provided by Clinical Practice Research Datalink records and Hospital Episode Statistics records from January 2007 to December 2015.

Participants Patients with asthma aged 18-80 years participated in this study.

Main outcome measures Eligibility for referral by the British Thoracic Society/Scottish Intercollegiate Guidelines Network (BTS/SIGN) 2016 guidelines, determined after a 3-month pharmacological therapy exposure assessment, was classed by either 'high-dose therapies', 'continuous or frequent use of oral steroids' or 'incident eligibility' during follow-up (continuous oral corticosteroids for more than 3 months, or $\geq 800 \mu \mathrm{g} /$ day inhaled corticosteroids/long-acting $\beta_{2}$-agonist (or three controllers) and $\geq 2$ asthma attacks/ year).

Results From the final cohort $(\mathrm{n}=23293), 19837$ patients were eligible for specialist referral during follow-up based on the BTS/SIGN guideline recommendations. Among eligible patients without any previously recorded referral, $4 \%$ were referred during follow-up, with a median waiting time of 880 days (IQR=1428 days) between eligibility and referral.

Conclusions A large number of patients with asthma were eligible for specialist referral, of which a small proportion were referred, and many experienced a long waiting time before referral. The results indicate a major unmet need in asthma referral, which is a potential source of preventable harm and are likely to have implications regarding how services are organised to address this unmet need.

\section{INTRODUCTION}

Asthma is a common and complex chronic inflammatory disease of the airways, which can lead to a significant burden for both
Strengths and limitations of this study

- The novel data reported in this study answer an important clinical question around asthma referral rates in primary care in England and may help us in the planning and implementation of improved healthcare services for people with asthma.

- Other strengths of the study include the use of a large data set and its breadth of coverage, as well as the use of a conservative approach to exclude missing data and the long study duration (mean follow-up period of 5.47 years).

- A limitation of the study may have been only using referral eligibility criteria (exacerbation frequency/medication use) based on the British Thoracic Society/Scottish Intercollegiate Guidelines Network guidelines, which may have omitted other rare causes of referral and could have led to a slight underestimation of the unmet need overall.

individuals and society. ${ }^{1}$ Appropriate management can reduce the risk of acute asthma attacks and airway remodelling while improving symptom burden and quality of life. ${ }^{23}$ One key aspect of asthma management is timely referral of patients with difficult-totreat asthma for a specialist opinion. Patients receiving care from asthma specialists have relatively low rates of hospitalisation and the potential for improved clinical outcomes, and the care provided is more likely to be consistent with national guidelines. ${ }^{4-6}$ Asthma specialists have more topic-specific training, more time allocated to spend with patients and greater access to a broader range of tests than primary care clinicians. These factors are combined with access to additional healthcare resources and advanced therapies in a closely regulated and audited manner. ${ }^{5-9}$ Referral can therefore lead to 
improved identification and remediation of factors that exacerbate asthma, including common comorbidities and treatment non-adherence, and an overall broad and effective care plan for patients.

Asthma management guidelines and recommendations provide guidance on when patients with asthma should be referred to a specialist. ${ }^{8}$ Despite these guidelines, lack of specialist referrals or failure to refer in practice is evident: a review of asthma management in the USA found that even though the majority of patients were uncontrolled, only $22 \%$ of patients visited a specialist for usual asthma care. ${ }^{10}$ Improvements in overall (global) asthma mortality rates have stalled over the last decade,$^{11}$ something which timely referral to specialist care may help to address. Indeed, the National Review of Asthma Deaths (NRAD) report identified that $19 \%$ of asthma deaths in the UK were associated with potentially avoidable factors related to specialist referral, such as delayed referral and failure to refer. ${ }^{12}$ However, little is known about how many patients meet the criteria for referral from primary care. This information could help identify the potential burden on secondary care services and help with resource allocation and workforce planning.

In this study, we aimed to compare primary care asthma referral patterns with guideline recommendations and thereby identify the unmet need in asthma referrals in England. We defined unmet need as the number of patients who are eligible for referral to a respiratory specialist in England, based on asthma management guidelines and recommendations, but who had not yet been referred. The primary objectives of this study were to quantify this unmet need, identify the proportion of those eligible patients who were referred and determine the waiting time to their first referral.

\section{METHODS}

\section{Data source}

This observational cohort study was based on routinely collected healthcare data provided by Clinical Practice Research Datalink (CPRD) ${ }^{13}$ and Hospital Episode Statistics (HES) ${ }^{14}$ records from January 2007 to December 2015. CPRD is a primary care database with anonymised records from general practitioners (GPs) and covers over 11.3 million patients in the UK, of which 4.4 million patient records (alive and currently registered) meet the quality criteria (data quality is driven by the Quality and Outcomes Framework in the UK and monitored by CPRD internal processes); this constitutes approximately $6.9 \%$ of the UK population from across the country. ${ }^{13}$ The HES database contains details of admissions, emergency department attendances and outpatient appointments at National Health Service (NHS) hospitals in England, and has patient-level linkage to approximately $60 \%$ of CPRD practices. ${ }^{1415}$ Given the broad coverage of CPRD and HES records, results of this study are expected to be nationally representative of the overall population of England. For this study, we have linked primary care records and practice-level socioeconomic status (index of multiple deprivation) from CPRD and admitted patient care and outpatient data from HES.

\section{Study population}

The study population consisted of all patients with an asthma diagnosis who were registered with a GP during the study period. Inclusion criteria for the study were adult patients aged 18-80 years at study start, either with a pre-existing diagnosis or who had been newly diagnosed with asthma during the study according to asthma diagnostic Read codes (online supplementary table 1$),{ }^{16}$ and with one full year of data prior to the index date (defined as the last day of the 3-month period for assessing baseline treatment regimen; please see below for further details). This 1-year minimum look-back period was to ensure that patients' medical history and any relevant comorbid conditions could be assessed. Patients must have been registered at a CPRD practice with acceptable quality standard records (quality flag derived from an algorithm considering gender, birth year, events prior to birth year, extreme age values, missing data and registration dates in general practice) and belong to practices consenting for linkage with HES data. Patients participating in a clinical trial during the study period (as determined by Read codes) or with a diagnosis code of chronic obstructive pulmonary disease within 1 year prior to index were excluded.

\section{Study design}

Individuals were entered into the study from January 2007 or subsequently once they met eligibility criteria. At baseline, treatment stages were assessed during the first 3 months of observation (ie, study start plus 3 months) or within 3 months of diagnosis for patients diagnosed during the study period, using pharmacological therapy Read codes (which are available on request). The last day of the 3-month baseline assessment period was termed the 'index date'. For analysis, patients were assigned to pharmacological therapy categories based on the British Thoracic Society/Scottish Intercollegiate Guidelines Network (BTS/SIGN) 2016 guidelines. Patients only on a single regular preventer or low-dose inhaled corticosteroids (ICS) with an initial add-on therapy were excluded. The final cohort only included patients who were on either 'additional add-on therapies', 'high-dose therapies' or 'continuous or frequent use of oral steroids' (at least two prescriptions within the 3-month assessment period with a duration of $\geq 28$ days; treatment details are shown in table 1 ).

In the 2014 BTS/SIGN guidelines, these categories were known as step 3 (for additional add-on therapies), step 4 (for high-dose therapies) and step 5 (for continuous or frequent use of oral steroids). ${ }^{17}$ Follow-up began at the index date and continued until the first of either end of registration in practice, end of study or death (figure 1).

Based on the BTS/SIGN 2016 guideline recommendations, patients were identified as eligible for referral if they 
Table 1 Categorisation of patients by pharmacological therapy during the 3-month assessment period

\begin{tabular}{ll}
\hline Category & Treatment options \\
\hline Additional add-on therapies (previously step $3^{*}$ ) & LABA+1 or more: LTRA, LAMA, theophylline or chromones \\
& ICS+1 or more: LABA, LTRA, LAMA or theophylline \\
High-dose therapies (previously step $4^{*}$ ) & LABA, LTRA, LAMA, theophylline or chromones \\
& $>800 \mu \mathrm{g}$ ICS/LABA \\
Continuous or frequent use of oral steroids (previously step $5^{*}$ ) & $>\geq 800 \mu \mathrm{g}$ ICS, OCS+other treatment \\
\hline
\end{tabular}

ICS are in BDP equivalent dose.

${ }^{*}$ Corresponding names of categories in the 2014 British Thoracic Society/Scottish Intercollegiate Guidelines Network guidelines.

BDP, beclomethasone dipropionate; ICS, inhaled corticosteroids; LABA, long-acting $\beta_{2}$-agonist; LAMA, long-acting muscarinic antagonist; LTRA, leukotriene receptor antagonists; OCS, oral corticosteroid.

were on 'high-dose therapies' or 'continuous or frequent use of oral steroids'. Patients could also have 'incident eligibility' during the follow-up period if they had continuous oral corticosteroid (OCS) use for $>3$ months, or high-dose ICS/long-acting $\beta_{2}$-agonists (LABAs) (or three controller medications) and $\geq 2$ asthma attacks in a year (based on asthma Read codes).

\section{Outcomes}

The primary outcome of the study was to estimate the unmet need in asthma referral, that is, the proportion of eligible patients not referred, and the waiting time patients experienced between eligibility and their first referral. A list of Read codes was used to screen the CPRD referral records to identify the eligible patients who were referred during the study period (online supplementary table 2). The secondary outcome was to identify predictors of a patient's time to referral.

\section{Statistical, survival and sensitivity analysis}

Analysis was carried out to compare baseline characteristics between age groups, gender and treatment stages; a $\chi^{2}$ test was performed and $95 \%$ CI calculated. Histograms and percentages were used to display data. Survival analysis models were used to estimate predictors of the time to

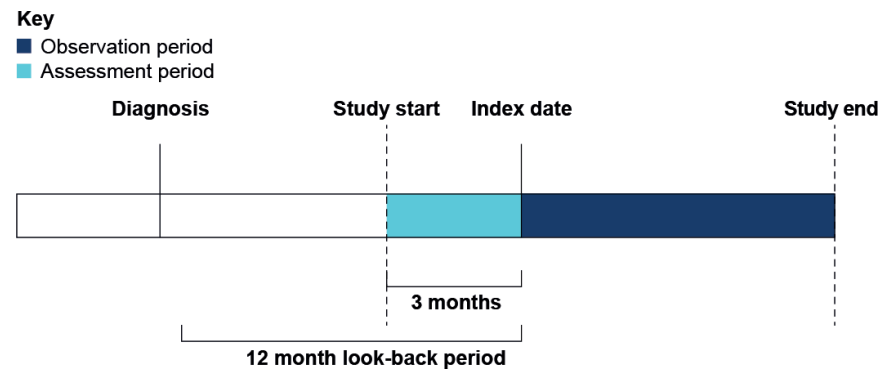

Figure 1 Study design of UNTWIST. Patients were observed from the index date (last day of the 3-month period for BTS/SIGN assessment) until the first of either end of study period, death, patient's transfer out of practice or practice last collection date. To be eligible, patients had to have data for one full year prior to the index date (12-month lookback period). BTS/SIGN, British Thoracic Society/Scottish Intercollegiate Guidelines Network. referral for a patient. Sensitivity analyses were performed with additional definitions of unmet need and waiting time (online supplementary figure 1 ).

This study was reviewed and approved by the Independent Scientific Advisory Committee for Medicines and Healthcare products Regulatory Agency database research (Ref: 17_026R) and an internal scientific committee of the study sponsor.

\section{Patient and public involvement statement}

Neither patients nor the public were involved in the design or planning of the study.

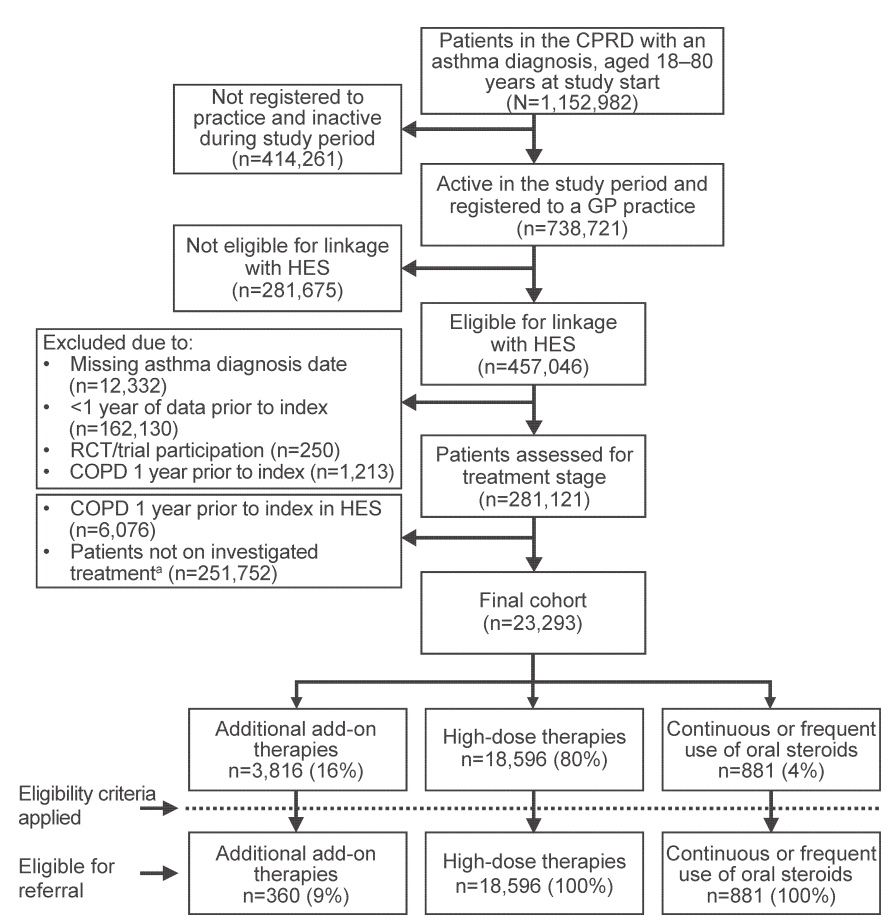

Figure 2 Cohort selection and referral eligibility of patients in UNTWIST. a For a description of investigated treatment regimens, see table 1. COPD, chronic obstructive pulmonary disease; CPRD, Clinical Practice Research Datalink; GP, general practitioner; HES, Hospital Episode Statistics; RCT, randomised controlled trial. 


\section{RESULTS}

\section{Cohort selection and baseline characteristics}

At study start (January 2007), 1152982 patients with recorded asthma diagnosis who were aged 18-80 years and registered with a CPRD practice were identified. Of these, 23293 patients were included in the final cohort after exclusion criteria were applied, with the majority of patients receiving high-dose therapies (figure 2). The final study cohort was composed of $60 \%$ females; the mean age of the population at index was 50 years ( $\mathrm{SD}=14$ years); $57 \%$ of the cohort had a body mass index (BMI) $\geq 25 \mathrm{~kg} / \mathrm{m}^{2}$, and $28 \%$ of the cohort reported being current smokers. Distribution of patients across most regions of England was roughly even, with a similar percentage of patients across all three categories of 'additional add-on therapies', 'high-dose therapies' and 'continuous or frequent use of oral steroids' (table 2). Patients were equally spread across the five deprivation quintiles. The mean follow-up time for individuals was 5.47 years $(\mathrm{SD}=2.92$ years $)$.

Eligibility for referral to respiratory specialist

Eligibility criteria based on the BTS/SIGN 2016 guidelines was applied to the final cohort of 23293 patients during the follow-up period and 19837 patients were

Table 2 Demographics and baseline characteristics of study cohort

\begin{tabular}{|c|c|c|c|c|}
\hline \multirow[b]{2}{*}{ Baseline characteristics } & \multirow[b]{2}{*}{$\begin{array}{l}\text { All patients } \\
(\mathrm{n}=23293)\end{array}$} & \multicolumn{3}{|c|}{ Medication category } \\
\hline & & $\begin{array}{l}\text { Additional add-on } \\
\text { therapies } \\
(n=3816)\end{array}$ & $\begin{array}{l}\text { High-dose } \\
\text { therapies } \\
(n=18596)\end{array}$ & $\begin{array}{l}\text { Continuous or } \\
\text { frequent use of oral } \\
\text { steroids ( } n=881 \text { ) }\end{array}$ \\
\hline Female, n (\%) & $13879(60)$ & $2471(65)$ & $10855(58)$ & $553(63)$ \\
\hline Mean age at index, (SD) & $50(14)$ & $50(14)$ & $50(14)$ & $53(13)$ \\
\hline \multicolumn{5}{|l|}{ BMI $\left(\mathrm{kg} / \mathrm{m}^{2}\right), \mathrm{n}(\%)$} \\
\hline Underweight & $272(1)$ & $51(1)$ & $203(1)$ & $18(2)$ \\
\hline Normal weight & $4710(20)$ & $783(21)$ & $3751(20)$ & $176(20)$ \\
\hline Overweight & $6092(26)$ & $988(26)$ & $4886(26)$ & $218(25)$ \\
\hline Obese & $5796(25)$ & $922(24)$ & $4633(25)$ & $241(27)$ \\
\hline Severely obese & $1378(6)$ & $235(6)$ & $1079(6)$ & $64(7)$ \\
\hline \multicolumn{5}{|l|}{ Smoking status, n (\%) } \\
\hline Current smoker & $6610(28)$ & $955(25)$ & $5392(29)$ & $263(30)$ \\
\hline Non-smoker/never & $13618(58)$ & $2335(61)$ & $10779(58)$ & $504(57)$ \\
\hline Ex-smoker & $2961(13)$ & $512(13)$ & 2337 (13) & $112(13)$ \\
\hline \multicolumn{5}{|l|}{ Region, n (\%) } \\
\hline North East & $528(2)$ & $79(2)$ & $423(2)$ & $26(3)$ \\
\hline North West & $4208(18)$ & $600(16)$ & $3463(19)$ & $145(16)$ \\
\hline Yorkshire and The Humber & $1139(5)$ & $146(4)$ & $964(5)$ & $29(3)$ \\
\hline East Midlands & $942(4)$ & $95(2)$ & $815(4)$ & $32(4)$ \\
\hline West Midlands & 2912 (13) & 479 (13) & 2317 (12) & $116(13)$ \\
\hline East of England & 2402 (10) & $485(13)$ & $1815(10)$ & $102(12)$ \\
\hline South West & 3079 (13) & $567(15)$ & 2357 (13) & $155(18)$ \\
\hline South Central & $3283(14)$ & 475 (12) & $2669(14)$ & $139(16)$ \\
\hline London & $2356(10)$ & $412(11)$ & $1879(10)$ & $65(7)$ \\
\hline South East Coast & $2444(10)$ & $478(13)$ & $1894(10)$ & $72(8)$ \\
\hline $\begin{array}{l}\text { Mean number of OCS prescriptions in the } \\
\text { year prior, (SD) }\end{array}$ & $2(5)$ & $3(7)$ & $2(3)$ & $12(12)$ \\
\hline Mean eosinophil count (×109/L), (SD) & $0.24(0.13)$ & $0.24(0.13)$ & $0.24(0.13)$ & $0.24(0.14)$ \\
\hline \multicolumn{5}{|l|}{$\begin{array}{l}\text { Asthma attacks in the year prior, } \\
\mathrm{n}(\%)\end{array}$} \\
\hline 1 & $1492(6)$ & $275(7)$ & $1074(6)$ & $143(16)$ \\
\hline 2 or more & $489(2)$ & $124(3)$ & $260(1)$ & 105 (12) \\
\hline $\begin{array}{l}1+\text { asthma hospitalisations in the year } \\
\text { prior, } n(\%)\end{array}$ & $872(4)$ & $138(4)$ & $666(4)$ & $68(8)$ \\
\hline
\end{tabular}

BMI, body mass index; OCS, oral corticosteroid. 


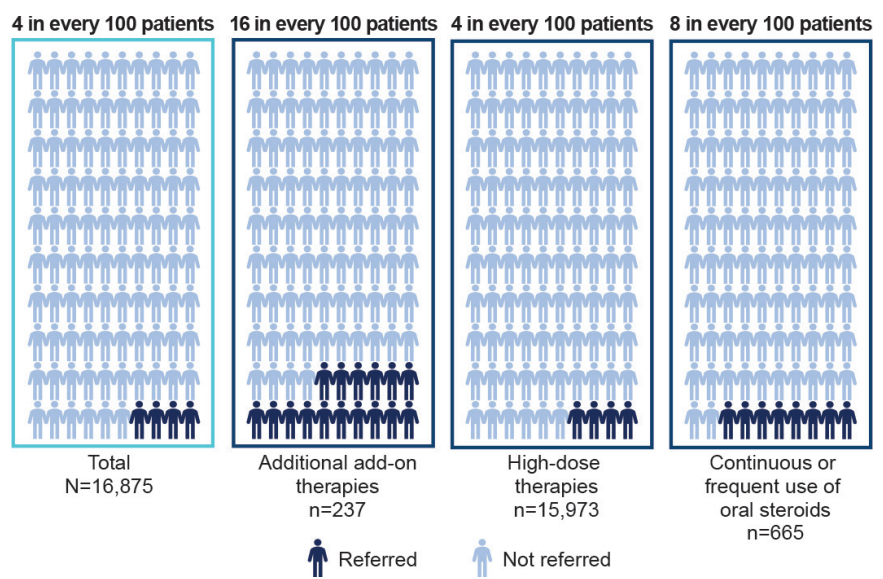

Figure 3 Unmet need for referral: referrals among patients who were eligible for referral for their asthma and had not previously been referred. Each block represents all the patients in the study who were eligible for referral and had not previously been referred.

identified as eligible for specialist referral: $9 \%$ of patients from 'additional add-on therapies', and all patients from 'high-dose therapies' or 'continuous or frequent use of oral steroids' (figure 2).

\section{Unmet need for asthma referral during the follow-up period}

Among the patients who were eligible for referral, $85 \%$ $(n=16875)$ had never been referred based on full medical records; of these, $723(4 \%)$ patients had their first referral during the study period ( $16 \%$ of patients from 'additional add-on therapies', $4 \%$ of patients from 'high-dose therapies' and $8 \%$ of patients from 'continuous or frequent use of oral steroids') (figure 3). For baseline characteristics of eligible patients without prior referral who were referred versus patients who were not referred, see online supplementary table 3 .

\section{Time waiting for first referral to respiratory specialist}

The median waiting time from eligibility (index date or date of incident eligibility) to the date they were referred was 880 days (IQR=1428 days; figure 4$)$.

\section{Factors associated with time waiting for referral}

A longer waiting time for referral was associated with higher BMI $(\mathrm{p}<0.001)$, deprivation quintile (deprivation was calculated based on patient postcode; longer waiting times in more deprived areas; $\mathrm{p}<0.001$ ), prescription of OCS (any use of OCS prior to index; patients with a prescription had a higher waiting time; $\mathrm{p}=0.031$ ), index season (longest waiting time during January-March compared with October-December; $\mathrm{p}<0.001$ ), regional location (variation in waiting times across locations; $\mathrm{p}<0.001$ ) and index year (decreasing waiting times for more recent referrals; $\mathrm{p}<0.001)$.

\section{Sensitivity analyses}

A sensitivity analysis for eligibility for referral-using a definition of eligibility based solely on 'incident eligibility' during the follow-up period (ie, unstable patients

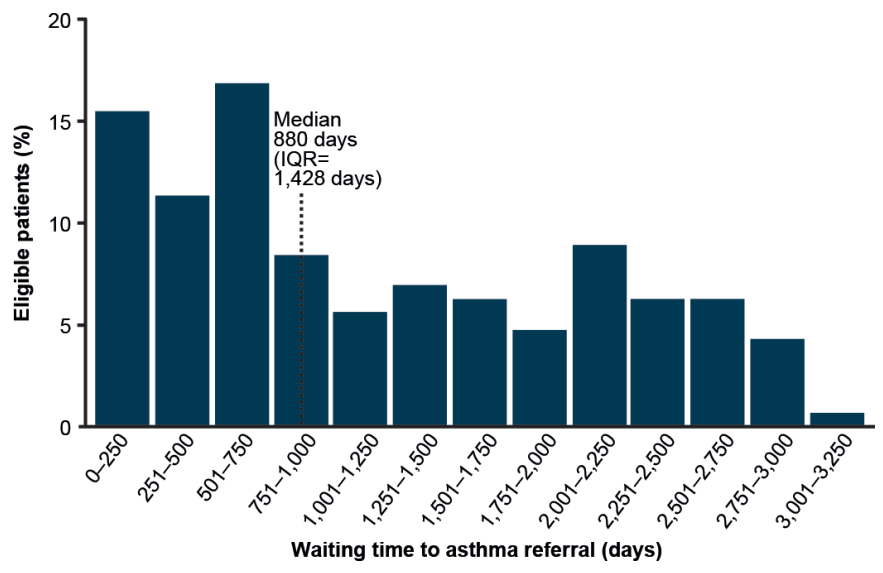

Figure 4 Waiting time to first referral during the follow-up period between 2007 and 2015 for eligible patients without any previous referrals, $n=628$. Total represents all patients who were eligible for referral without any previous referrals and had their first referral during the follow-up period between 2007 and 2015.

as indicated by continuous use of OCS for $>3$ months, or use of high-dose ICS/LABA (or three controller medicines) and $\geq 2$ asthma attacks in a year), and not including all 'high-dose therapies' and 'continuous or frequent use of oral steroids' patients automatically-identified 1617 patients (7\% of final cohort) as eligible for referral (online supplementary figure 1). Among those who had their first referral during the study period $(n=232$, $14 \%$ ) - using the above definition for referral eligibilitythe median wait time was 861 days ( $\mathrm{IQR}=1363$ days).

A separate sensitivity analysis for those receiving a referral-in which referrals were analysed by a broader range of Read codes (compared with a more restrictive list for the main analysis), including referral records containing asthma diagnosis codes (online supplementary table 1$)$-showed that $11 \%(n=2154)$ of all eligible patients were referred, with a median wait time to first referral of 1048 days (IQR=1490 days; online supplementary figure 1 ).

\section{DISCUSSION}

This study identified that a large number of patients were eligible for referral to respiratory specialists based on pharmacological therapy and exacerbation frequency as per the BTS/SIGN guideline recommendations. Of those eligible patients, only a small proportion (4\%) were referred to specialist care during the study period and many experienced a long wait before this happened. This appears to indicate a major unmet need in asthma care.

Numerous national and international guidelines and recommendations for asthma management, such as the Global Initiative for Asthma (GINA), ${ }^{8}$ BTS/SIGN guidelines ${ }^{18}$ and, in England, the National Institute for Health and Care Excellence (NICE) asthma quality standard, ${ }^{19}$ provide indications for specialist referral that broadly agree with the criteria for referral eligibility that we have used in our study. ${ }^{18}$ Despite such alignment in referral 
recommendations, our large-scale study suggests that patients with asthma are not being referred to specialists appropriately. This is consistent with findings from the NRAD study. ${ }^{12}$ The novelty in the design of our study, using nationally representative CPRD and HES data to estimate the unmet need in asthma referrals in England, adds to the findings of the NRAD study which used a smaller data set. Potential omission of further rare criteria for referral may mean that our study slightly underestimates the unmet need, although this gives the best overall estimate to date.

Suboptimal referral patterns are not unique to asthma. Other studies have found lower than expected referral rates for psoriasis, ${ }^{20}$ delayed referral for symptomatic gallstones ${ }^{21}$ and wide variation in referral rates for suspected gastrointestinal cancers. ${ }^{22}{ }^{23}$ Addressing this variation is central to initiatives such as Getting It Right First Time in the UK (http:/ /gettingitrightfirsttime.co.uk).

Previous studies have identified factors relating to clinician behaviour, ${ }^{8}$ financial pressures,${ }^{24}$ lack of coordination between different components of the healthcare system, ${ }^{25}$ and patient attitude and expectations ${ }^{26}$ as potential barriers to referral. It could also be that people with lower dose treatments experiencing exacerbations are more likely to be seen in secondary care than those who receive higher dose treatments but do not have frequent contact with healthcare professionals or unplanned admissions. In this study, deprivation quintile and regional location of patients were identified as predictors of longer waiting times to referral. These are consistent with findings from other studies that identified factors affecting waiting time for surgeries, ${ }^{27} 28$ and in England may be explained by regional differences in access to NHS services. We also found higher BMI to be associated with longer waiting time to referral: one explanation for this could be due to the overattribution of symptoms to obesity itself, ${ }^{29}$ thereby leading to a delay in onward referral or in progressing asthma management.

To address this unmet need, actions such as improving knowledge of referral criteria, ${ }^{30}$ incentivising early review ${ }^{31}$ and joint protocols between primary and secondary healthcare ${ }^{25}$ might be initiated, as these have been shown to be effective in other countries. Initiatives such as the SIMPLES algorithm can be used in primary care to guide comprehensive review of patients to clarify which patients should be referred. ${ }^{32}$ The algorithm involves assessment of smoking status, inhaler technique, monitoring (by both healthcare professionals and patients themselves), pharmacotherapy, lifestyle, education and the support needs of patients, and can act as a 'red flag' system in the primary care setting to proactively identify and systematically review patients on high-dose therapies, especially those who fail to achieve asthma control or have frequent exacerbations. ${ }^{32}$ This can help prevent inappropriate treatment escalation, stepping down treatment where necessary, and identify patients for referral as per guideline recommendations. However, such initiatives must also be balanced against available provision of specialist resources. Improved targeting of those patients most likely to benefit from review will require further evidence-based research. There are 1.86 adult respiratory physicians per 100000 people in the UK, which is below the European mean of 4.4 adult respiratory physicians per 100000 people. ${ }^{33}$ A large upswing in specialists might be needed to meet current guideline recommendations and address the backlog of asthma referrals identified in this study.

Our sensitivity analysis showed that if we limit eligibility to 'incident eligibility' criteria alone (see the Methods section for full definition), $7 \%$ of the final cohort is deemed eligible for referral, of which only $14 \%$ were referred. The higher percentage of referred patients in comparison to the main analysis suggests that practitioners may be more likely to consider referral when escalating therapy, but that practitioners should still consider referring patients who are already on high-dose treatment as per guideline recommendations.

The strengths of this study lie in the breadth of the coverage (as data taken from CPRD and HES records are expected to be nationally representative of the overall UK population) ${ }^{13}$ quality of data (conservative approach taken to exclude missing data) and long study duration (mean follow-up period $>5$ years, with a 1-year look-back period from index date).

However, there are a number of limitations. The study underestimates the number of patients with asthma that were eligible for referral, as referral criteria were based on medication use and exacerbation frequency. However, the real-world data do not assess the appropriateness of the therapy and we acknowledge there may be possible underprescription or overprescription of therapy. We did not include other referral criteria suggested in GINA and BTS/SIGN guidelines, such as diagnostic uncertainty, occupational asthma or presence of other complications. In addition, our study has excluded those patients on therapy lower than 'additional add-on' therapy at index date whose asthma may have been declining during the study period and who subsequently become eligible for referral. Eligibility criteria for referral in this study were based on the BTS/SIGN guidelines only. However, the criteria we have used are consistent across many national and international guidelines and recommendations, ${ }^{8}$ including NICE asthma quality standards and GINA. ${ }^{19} 34$ We used a long study period (2007-2015) to enrich the study population and allow sufficient follow-up time to assess referrals. However, the long study duration also meant updates were made to guidelines over the study period. Our referral criteria were based on the more recent 2016 BTS/SIGN guidelines, to ensure coverage of all the medicines that could have been used in the study period. ${ }^{35}$ In addition, to operationalise the guidelines using electronic health records, we applied a pragmatic approach to therapy combinations in our allocation of patients to treatment categories. In a sensitivity analysis, we identified 1378 patients who were on exactly $800 \mu \mathrm{g}$ ICS/LABA. However, as this was a small proportion $(7 \%)$ 
of the eligible-for-referral population, we do not think that this significantly impacts the major findings of this study.

We acknowledge that prescription Read code indicates a prescription was made, but we cannot know whether the prescription was collected. In addition, electronic health records do not reveal whether patients have been adherent or administered their medication correctly. Additionally, prescriptions may not have been stepped down or updated after an acute exacerbation treatment. However, we believe these are limitations beyond the scope of this study, and the large data sets of CPRD and HES with robust Read codes are likely to provide an accurate representation of the unmet need in asthma referrals.

We have been able to identify that referrals are often not made, but qualitative studies are required to understand the reasons for this. Prospective studies are also needed to examine the impact of low referral rates and the extent to which the unreferred are harmed. Finally, health economics studies investigating the impact of more referrals will help inform on the balance of the cost of increasing specialist capacity compared with potentially reducing admissions and keeping people in work.

\section{CONCLUSION}

A significant unmet need in asthma care exists wherein the vast majority of patients who are eligible for referral based on guideline recommendations are not referred to specialist services, and those who are experience long delays. This is a potential source of preventable harm. We need to consider how we can improve compliance with guidelines while reflecting on how any increased demand would be met in secondary care. Alternatively, we can explore new models of care/recommendations.

\section{Author affiliations}

${ }^{1}$ Respiratory Medicine, Sir Charles Gairdner Hospital, Nedlands, Western Australia, Australia

${ }^{2}$ University of Liverpool Department of Health Services Research, Liverpool, UK ${ }^{3}$ Market Access, Boehringer Ingelheim Ltd, Bracknell, UK

${ }^{4}$ Medical Affairs, Boehringer Ingelheim Ltd, Bracknell, UK

${ }^{5}$ Department of Respiratory Medicine, Royal Liverpool and Broadgreen Hospitals NHS Trust, Liverpool, UK

${ }^{6}$ TA Respiratory/Biosimilars, Boehringer Ingelheim International GmbH, Ingelheim am Rhein, Germany

\section{Twitter Michael Baldwin @mikey3982}

Contributors AG, MGS, MB, JDB and GHJ planned/conducted the study. AG carried out the statistical analysis. All authors had full access to all the data in the study and contributed to the interpretation of results, revisions of the manuscript and approved the final manuscript. JB is the guarantor. Ishmam Nawar at MediTech Media provided editorial assistance in the development of the manuscript, funded by Boehringer Ingelheim.

Funding This study was funded by Boehringer Ingelheim. No restrictions have been placed on the choice of analyses or the interpretation of the results. All authors contributed to the study design and interpretation of data and were involved in the decision to submit the paper for publication. AG conducted data collection and analysis. The manuscript was written by Ishmam Nawar at MediTech Media under the conceptual direction of authors, funded by Boehringer Ingelheim.

Disclaimer JDB (lead author) affirms that the manuscript is an honest, accurate and transparent account of the study and no important aspects of the study have been omitted; and that any discrepancies from the study as planned (and, if relevant, registered) have been explained.

Competing interests In the last three years, JDB has received personal fees and non-financial support from Napp, AstraZeneca and Boehringer Ingelheim, and personal fees from Novartis and Teva, outside the submitted work. GHJ has received personal fees from Pfizer, AstraZeneca, Chiesi and GlaxoSmithKline, and non-financial support from Napp, outside the submitted work. AG was an employee of Boehringer Ingelheim at the time the study was carried out. MGS and MB are employees of Boehringer Ingelheim.

\section{Patient consent for publication Not required.}

Ethics approval These analyses were performed in accordance with relevant regulations/guidelines. This study was reviewed and approved by the Independent Scientific Advisory Committee for Medicines and Healthcare products Regulatory Agency database research (Ref: 17_026R) and an internal scientific committee of the study sponsor. As this was a non-interventional study using anonymised data, no patient consent was necessary.

Provenance and peer review Not commissioned; externally peer reviewed.

Data availability statement Data are available on request from the CPRD. Their provision requires the purchase of a licence, and our licence does not permit us to make them publicly available to all. We used data from the version collected in April 2017 and have clearly specified the data selected in our Methods section. To allow identical data to be obtained by others, via the purchase of a license, we will provide the code lists on request. Licences are available from the CPRD (http:// www.cprd.com): The Clinical Practice Research Datalink Group, The Medicines and Healthcare products Regulatory Agency, 5th Floor, 151 Buckingham Palace Road, Victoria, London SW1 W 9SZ.

Open access This is an open access article distributed in accordance with the Creative Commons Attribution Non Commercial (CC BY-NC 4.0) license, which permits others to distribute, remix, adapt, build upon this work non-commercially, and license their derivative works on different terms, provided the original work is properly cited, appropriate credit is given, any changes made indicated, and the use is non-commercial. See: http://creativecommons.org/licenses/by-nc/4.0/.

ORCID iD

Mariel G Slater http://orcid.org/0000-0003-0988-6146

\section{REFERENCES}

1 Bahadori K, Doyle-Waters MM, Marra C, et al. Economic burden of asthma: a systematic review. BMC Pulm Med 2009;9:24.

2 World Health Organization. Asthma fact sheet 307 . Available: http:// www.who.int/mediacentre/factsheets/fs307/en/ [Accessed 24 Jan 2018].

3 Bergeron C, Tulic MK, Hamid Q. Airway remodelling in asthma: from benchside to clinical practice. Can Respir J 2010;17:e85-93.

4 Diette GB, Skinner EA, Nguyen TT, et al. Comparison of quality of care by specialist and generalist physicians as usual source of asthma care for children. Pediatrics 2001;108:432-7.

5 Erickson S, Tolstykh I, Selby JV, et al. The impact of allergy and pulmonary specialist care on emergency asthma utilization in a large managed care organization. Health Serv Res 2005;40:1443-65.

6 Aragona E, Wang J, Scheckelhoff T, et al. Asthma specialty clinics decrease emergency department visits in inner-city children hospitalized for asthma exacerbation. Am J Respir Crit Care Med 2014;189:A3838.

7 American College of Allergy, Asthma and Immunology. Asthma management and the allergist: better outcomes at lower cost, 2015. Available: https://college.acaai.org/sites/default/files/Resources/ BlueBook/acaai_allergistsbluebook_f.pdf [Accessed 1 Sep 2018].

8 Price D, Bjermer L, Bergin DA, et al. Asthma referrals: a key component of asthma management that needs to be addressed. $J$ Asthma Allergy 2017;10:209-23.

9 National Health Services. Service specifications: specialised respiratory services (adult) - severe asthma. Available: https:// www.england.nhs.uk/wp-content/uploads/2017/04/specialisedrespiratory-services-adult-severe-asthma.pdf [Accessed 12 Nov 2018].

10 Murphy KR, Meltzer EO, Blaiss MS, et al. Asthma management and control in the United States: results of the 2009 asthma insight and management survey. Allergy Asthma Proc 2012;33:54-64.

11 Ebmeier S, Thayabaran D, Braithwaite I, et al. Trends in international asthma mortality: analysis of data from the who mortality database from 46 countries (1993-2012). Lancet 2017;390:935-45. 
12 Royal College of Physicians. Why asthma still kills: the National review of asthma deaths (NRAD). Available: https://www.rcplondon. ac.uk/projects/outputs/why-asthma-still-kills [Accessed 14 Jun 2017].

13 Herrett E, Gallagher AM, Bhaskaran K, et al. Data resource profile: clinical practice research Datalink (CPRD). Int J Epidemiol 2015;44:827-36.

14 Digital NHS. Hospital episode statistics (HES). Available: https:// digital.nhs.uk/data-and-information/data-tools-and-services/dataservices/hospital-episode-statistics [Accessed 4 May 2018].

15 Bloom Cl, Nissen F, Douglas IJ, et al. Exacerbation risk and characterisation of the UK's asthma population from infants to old age. Thorax 2018;73:313-20.

16 Nissen F, Morales DR, Mullerova H, et al. Validation of asthma recording in the clinical practice research Datalink (CPRD). BMJ Open 2017;7:e017474.

17 British Thoracic Society. British guideline for the management of asthma. Available: https://www.brit-thoracic.org.uk/documentlibrary/clinical-information/asthma/btssign-asthma-guideline-2014/ [Accessed Jan 2018].

18 British Thoracic Society. The BTS/SIGN guideline for the management of asthma. Available: https://www.brit-thoracic.org. uk/document-library/clinical-information/asthma/btssign-asthmaguideline-2016/ [Accessed 16 Jun 2017].

19 NICE. Asthma quality standard. Available: https://www.nice.org.uk/ guidance/qs25/chapter/Quality-statements [Accessed 1 Sep 2018]

20 Khalid JM, Globe G, Fox KM, et al. Treatment and referral patterns for psoriasis in United Kingdom primary care: a retrospective cohort study. BMC Dermatol 2013;13:9.

21 Borowski D, Knox M, Kanakala V, et al. Referral pathways of patients with gallstones: a potential source of financial waste in the U.K. National health service? Int J Health Care Qual Assur 2010;23:248-57.

22 Shawihdi M, Thompson E, Kapoor N, et al. Variation in gastroscopy rate in English general practice and outcome for oesophagogastric cancer: retrospective analysis of hospital episode statistics. Gut 2014;63:250-61.

23 John SKP, Jones OM, Horseman N, et al. Inter general practice variability in use of referral guidelines for colorectal cancer. Colorectal Dis 2007;9:731-5.
24 Cabana MD, Ebel BE, Cooper-Patrick L, et al. Barriers pediatricians face when using asthma practice guidelines. Arch Pediatr Adolesc Med 2000;154:685-93.

25 Orozco-Beltrán D, Carratalá-Munuera C, Arriero JM, et al. Management and referral of patients with severe and poorly controlled asthma in primary care. Fam Pract 2016;33:678-83.

26 Sastre J, Fabbri LM, Price D, et al. Insights, attitudes, and perceptions about asthma and its treatment: a multinational survey of patients from Europe and Canada. World Allergy Organ J 2016;9:13.

27 Liederbach E, Sisco M, Wang C, et al. Wait times for breast surgical operations, 2003-2011: a report from the National cancer data base. Ann Surg Oncol 2015;22:899-907.

28 Laudicella M, Siciliani L, Cookson R. Waiting times and socioeconomic status: evidence from England. Soc Sci Med 2012;74:1331-41.

29 Phelan SM, Burgess DJ, Yeazel MW, et al. Impact of weight bias and stigma on quality of care and outcomes for patients with obesity. Obes Rev 2015;16:319-26.

30 Haahtela T, Tuomisto LE, Pietinalho A, et al. A 10 year asthma programme in Finland: major change for the better. Thorax 2006;61:663-70.

31 Siciliani L, Moran V, Borowitz M. Measuring and comparing health care waiting times in OECD countries. Health Policy 2014;118:292-303.

32 Ryan D, Murphy A, Ställberg B, et al. 'SIMPLES': a structured primary care approach to adults with difficult asthma. Prim Care Respir J 2013;22:365-73.

33 European Respiratory Society. European lung white book. Chapter 33: medical respiratory specialists. Available: https:// www.erswhitebook.org/chapters/medical-respiratory-specialists/ [Accessed 29 Mar 2019].

34 Global Initiative for Asthma. GINA report: global strategy for asthma management and prevention. Available: http://ginasthma.org/ 2018-gina-report-global-strategy-for-asthma-management-andprevention/ [Accessed 22 Oct 2018].

35 British Thoracic Society, Scottish Intercollegiate Guidelines Network. British guideline on the management of asthma - a national clinical guideline; 2016. 